STUDI

FRANCESI

\section{Studi Francesi}

Rivista quadrimestrale fondata da Franco Simone

185 (LXII | II) | 2018

OCTAVE MIRBEAU: UNE CONSCIENCE AU TOURNANT

DU SIEECLE - sous la direction de Ida Merello

\title{
Flamenca. Texte édité d'après le manuscrit unique de Carcassonne par François ZUFFEREY et traduit par Valérie FASSEUR
}

\section{Giuseppe Noto}

\section{OpenEdition}

\section{Journals}

\section{Édition électronique}

URL : http://journals.openedition.org/studifrancesi/13169

DOI : 10.4000/studifrancesi. 13169

ISSN : 2421-5856

Éditeur

Rosenberg \& Sellier

\section{Édition imprimée}

Date de publication : 1 août 2018

Pagination : 298

ISSN : 0039-2944

\section{Référence électronique}

Giuseppe Noto, «Flamenca. Texte édité d'après le manuscrit unique de Carcassonne par François ZUFFEREY et traduit par Valérie fASSEUR », Studi Francesi [En ligne], 185 (LXII | II) | 2018, mis en ligne le 01 septembre 2018, consulté le 06 janvier 2021. URL : http://journals.openedition.org/studifrancesi/ 13169 ; DOI : https://doi.org/10.4000/studifrancesi.13169

Ce document a été généré automatiquement le 6 janvier 2021.

\section{(c)}

Studi Francesi è distribuita con Licenza Creative Commons Attribuzione - Non commerciale - Non opere derivate 4.0 Internazionale. 


\title{
Flamenca. Texte édité d'après le manuscrit unique de Carcassonne par François ZUFFEREY et traduit par Valérie FASSEUR
}

\author{
Giuseppe Noto
}

\section{RÉFÉRENCE}

Flamenca. Texte édité d'après le manuscrit unique de Carcassonne par François zUFFEREY et traduit par Valérie FASSEUR, Paris, Le Livre de poche (Librairie Générale Française), 2014, pp. 638.

1 Dopo le recenti edizioni per le cure di Roberta Manetti (2008, con traduzione in italiano) e di Jaime Covarsí Carbonero (2010, con traduzione in spagnolo), dobbiamo a François Zufferey una nuova edizione critica di quella che appare certamente come uno dei massimi enigmi esegetici della letteratura medievale in lingua d'oc. Trasmessa da un solo testimone e in forma incompleta, l'opera è conosciuta di norma con un titolo (Flamenca, appunto) che le diede François Raynouard (all'epoca indiscussa autorità in materia) quando, nel 1834, portò alla luce il frammento costituito da 8095 versi.

2 L'edizione, condotta secondo criteri estremamente conservativi («Comment éditer un texte transmis par un témoin unique? Une règle s'impose, qui invite l'éditeur à intervenir le moins possible et à respecter les leçons du copiste, pour autant que le texte critique offre un sens satisfaisant», p. 111), è preceduta da una densissima e assai utile introduzione (pp. 9-113) firmata dallo stesso Zufferey (per le parti di ordine codicologico e filologico-linguistico) e da Valérie Fasseur (per le parti di ordine storicoletterario). Fasseur cura anche la traduzione posta a fronte del testo critico (pp. 127-613). 
3 Davvero ben organizzata la bibliografia esibita al fondo dell'introduzione (pp. 113-126). Completano il volume alcune utili schede sulla topografia di Bourbon alla fine del XIII secolo, comprensive di disegni e mappe (pp. 615-622), un Index des noms propres (pp. 622-632), una Liste des proverbes (p. 633) e una schematizzazione della Structure en triptyque dei circa 8000 versi conservati (p.635). 